\title{
LITERATURA CONTEMPORÂNEA BRASILEIRA, PRÊMIOS LITERÁRIOS E LIVROS DIGITAIS: UM PANORAMA EM MOVIMENTO
}

RESUMO: Neste artigo, tecemos uma articulação entre mecanismos de legitimação de obras literárias relacionados a prêmios. Prêmios literários existem há mais de meio século no Brasil, no entanto são muito mais comuns e difundidos na contemporaneidade. Também abordamos a relação, ainda incipiente, entre prêmios literários considerados importantes e obras de literatura digital. Concluímos que os prêmios nacionais começam a admitir obras digitais, em algumas poucas situações e categorias, mas ainda timidamente. Enquanto isso, as poucas iniciativas em e-books literários se valem dos prêmios para se legitimar enquanto novo modelo de negócio e de edição.

PALAVRAS-CHAVE: livro digital; prêmios literários; produção editorial; literatura brasileira contemporânea.

ABSTRACT: This paper discusses some legitimation mechanis$\mathrm{ms}$ of literature and its relations with national and local prizes. Brazil have some literary prizes since 1960 , but not like nowadays, when they occur much more frequently. We also discuss here the new links between important literary prizes and digita books. We conclude that national prizes starts to admit digital books, in a few situations and categories, but yet in an incipient way. Meanwhile, the few initiatives in literary e-books uses the prizes to legitimize themselves as a new business and publishing model.

KEYWORDS: digital book; literary prizes; publishing; contemporary brazilian literature. 


\section{ALGUMAS CONSIDERAÇÕES SOBRE LITERATURA MERCADO E LEGITIMAÇÃO}

Vamos iniciar esta breve reflexão por algo que pode soar óbvio, mas que nos parece necessário retomar: a literatura brasileira tem sido, há décadas, produzida por escritores e editada em livros impressos, por meio de autopublicação, pequenas casas editoriais ou alguns poucos grandes grupos de edição. $\mathrm{Na}$ atualidade, a tecnologia empregada para isso não difere muito de um desses espaços para outro. E a circulação dos livros continua sendo uma questão difícil para todos, menos um tanto para as editoras grandes, que têm nas mãos não apenas modos de distribuição mais efetivos - porque têm dinheiro -, mas também influência sobre a imprensa, os curadores de eventos importantes, etc. Disso decorre que os livros lançados por editoras grandes costumam se fazer um pouco mais conhecidos de certo público, assim como seus autores, o que configura um cenário concentrado e bastante repetitivo. Neste artigo, não focalizaremos os autores ou os editores, mas os livros, especialmente os digitais, e os prêmios literários.

Muniz Junior ${ }^{1}$ nos oferece uma mirada sociológica para pensar os prêmios literários como uma questão de produção e circulação de valor simbólico (mas também outros). Domingues e Vieira ${ }^{2}$ apontam as antologias, os eventos e os prêmios como peças no tabuleiro da legitimação literária. No caso destes últimos, os mais importantes oferecem valores consideráveis em dinheiro. Há pelo menos dois tipos de prêmios literários comuns no Brasil: (a) para livros inéditos, geralmente inscritos sob pseudônimo, que ajudam a revelar obras e autores ao país, aos editores e às editoras que estejam atentas aos resultados; e (b) os oferecidos a obras e autores já publicados. Neste caso, tais premiações ajudam a reiterar ou a legitimar, cada vez mais, livros que já circulam. Não é de se desprezar a informação de que a maior parte dos livros ganhadores desses prêmios seja já de editoras grandes, duas ou três no cenário brasileiro atual. Mais raramente, os prêmios têm formatos híbridos, oferecendo-se a inéditos e publicados, a um só tempo.

Entre os prêmios dados a obras e autores sob pseudônimo, Domingues e Vieira mencionam o Zaffari \& Bourbon, oferecido desde 1999 por uma rede de supermercados que atua no sul do país em parceria com a Jornada Literária de Passo Fundo; o Portugal Telecom, atualmente Oceanos, aberto à comunidade lusófona; o LeYa, oferecido por uma editora portuguesa desde 2008 para distinguir exclusivamente romances; ${ }^{3}$ o Prêmio São Paulo de Literatura, oferecido pelo governo de São Paulo desde 2008; o Jabuti, láurea da Câmara Brasileira do Livro desde o final dos anos 1950; os prêmios literários da Fundação Biblioteca Nacional; e o Prêmio Sesc, em parceria com a editora Record, sediada no Rio de Janeiro. Dos sete prêmios mencionados pelas autoras e considerados por elas os "de mais destaque no país" ${ }^{4}$ apenas o Sesc e o LeYa estimulam a concorrência de obras inéditas de autores não identificados de antemão, o que
3. Ver em $<$ https://goo.gl/XeTXrr $>$.

4. DOMINGUES; VIEIRA. O circuito do livro: formas de acesso à literatura na contemporaneidade (Brasil anos 2000), p. 84.
EM TESE
BELO HORIZONTE
v. 22
N. 3
SET.-DEZ. 2016
RIBEIRO. Literatura contemporânea brasileira, prêmios literários e livros [... ] P. 122-138 
5. Sobre a bibliodiversidade, ver MIHAL. Bibliodiversidad: una mirada a las políticas culturales estatales.

\section{Apenas para uma noção, o Jabuti} de 2016 cobrava $R \$ 450,00$ por partiçipação de autores e editores em condiç̃óes mais frágeis para em condiçoes mais frágeis para

menores solicitaram, abertamente,

via redes sociais, que seus autores inscrevessem os livros. parece aumentar as chances de algum movimento renovador e bibliodiverso ${ }^{5}$ da literatura brasileira e lusófona. As demais premiações mencionadas são para obras já em circulação, geralmente os mesmos autores, em poucos casos, revelações, o que pode ser entendido como um ciclo lento, e não apenas uma crítica à maneira como o valor circula.

O material apreciado por júris e críticos, no caso dos prêmios oferecidos a livros publicados, é formado pelas próprias obras, geralmente inscritas e enviadas pelas editoras. Nesse sentido, editoras menores mal conseguem competir, já que em alguns casos, as inscrições de seus autores teriam custo considerável. ${ }^{6}$ No caso dos concursos de obras inéditas, geralmente são os próprios autores, sob pseudônimo, que enviam o material e se inscrevem, a fim de concorrerem a alguma quantia em dinheiro e a certa visibilidade (geralmente efêmera), caso a premiação seja "de destaque", como é o caso de vários desses prêmios e de muitos outros não mencionados por Domingues e Vieira. Em todos os casos de prêmios a obras publicadas, parece claro o que seja um livro nesse universo da produção editorial. Aprofundemo-nos na questão.

\section{LIVROS E LIVROS DIGITAIS LITERÁRIOS}

Normalmente, a experiência com livros literários não é descartável. Talvez esse seja um critério, inclusive, para identificar a literariedade de uma obra. Da obra que não termina de ser relida, sempre chamada ao presente, fazendo sentido conforme a experiência de linguagem que o leitor vive, à obra que precisa estar exposta em um espaço de coleção, de memória, de atualização. Uma obra que se empresta, mas que se deseja ter de volta. Uma obra mais que livro, um verdadeiro ritual, desde a sua criação até a sua infindável leitura, por um ou por muitos.

Desde a sua concepção, o livro literário é envolto em rituais. E todos eles dizem respeito ao que a humanidade atribui ao livro e a si mesma em relação a ele..$^{7} \mathrm{O}$ "lançamento", por exemplo, de um livro digital desveste-se de quase tudo o que um livro impresso carrega de simbólico e de experiência material para se tornar uma espécie de encontro sem objeto. O que é um livro com um autógrafo? Quanto de sentido há nisso? Já vínhamos tentando nos localizar nesse cenário quando elencamos algumas situações em texto anterior. ${ }^{8}$ Dizíamos, sobre o livro e outros devices:

Desde o advento (valha o termo) dos aparelhos com telas mostradoras (sejam eles pesados computadores de mesa ou os hodiernos tablets) que os livros vêm servindo de metáforas para produtos legíveis que em quase nada se parecem com livros de papel, não fosse uma conexão de origem com um processo editorial já antigo. E além deste, uma relação visual, isto é, de planejamento gráfico, em muito coincidente e herdeira do livro impresso (muito embora nem sempre isso seja admitido). A relação entre novos e conhecidos objetos, no entanto, não
7. Em entrevista a Fernando Bogado ("Dos hombres y un libro

interminable"), Carlo Ginzburg e Roger Chartier consideram o livro da formação da cultura ocidental.

8. RIBEIRO. Ler na tela: o que é, hoje, um livro?.
EM TESE
BELO HORIZONTE
v. 22
N. 3
SET.-DEZ. 2016
RIBEIRO. Literatura contemporânea brasileira, prêmios literários e livros [... ] P. 122-138 
9. RIBEIRO. The book is on the tablet: visadas no discurso sobre o livro digital na imprensa, p. 3.

10. Ver RIBEIRO. Ler na tela: o que é, hoje, um livro?; RIBEIRO. O que é e o que não é um livro. editoriais; RIBEIRO Questões provisórias sobre literaturae tecnologia: um diálogo com Roger Chartier. Chartier

11. No original: "A book is a nonperiodical printed publication of at least 49 pages, exclusive of the cover pages, published in the country and made available to the public". ocorre sem tensionamentos. Tanto o leitor quanto, principalmente, o produtor de ambos (para desconsiderar qualquer híbrido) debatem sobre modos de usar, processos de feitura, usos e práticas, costumes e aprendizagens. Nesse cenário, a imprensa noticia, especialmente em cadernos de cultura (ou, hoje, de tecnologia), o lançamento deste ou daquele livro, em versões impressa e digital. Isso se faz, no entanto, com implicações para a formação e/ou a difusão de um discurso em relação à tecnologia e ao livro. ${ }^{9}$

No estudo mencionado, tratávamos de mostrar o quanto o livro impresso ainda é hegemônico no cenário da produção literária brasileira. Mesmo para autores que começam, se lançam e ficam conhecidos em canais digitais, é possível e provável que venham a lançar livros de papel em etapa posterior, como que a selar o reconhecimento como escritores, inclusive e principalmente para si mesmos. Mesmo com best-sellers con siderados pouco literários ou completamente trend isso ocorre. Um livro, muito embora exista em várias tecnologias, em diversos ambientes de circulação, continua sendo uma espécie de patrimônio a ser alcançado nas redes editoriais.

Para mencionar apenas uma definição que nos tem intrigado, ${ }^{10}$ vejamos a da Unesco, publicada no site da instituição e em vigor ainda hoje: "Um livro é uma publicação impressa não periódica com pelo menos 49 páginas, entre capas exclusivas, publicada no país e disponibilizada ao público". ${ }^{11}$
O documento da Unesco é uma recomendação de padronização de definições para facilitar estatísticas e comparações entre países. O que pretendemos ver destacado nessa recomendação é que os livros sejam inequivocamente impressos para serem considerados livros. O texto da Unesco é de 1964 quando as questões ligadas ao livro digital ainda não podiam ser sequer imaginadas.

Em relação aos livros eletrônicos, é no sociólogo John B. Thompson ${ }^{12}$ que vamos nos fiar para admitir que o mercado editorial de obras digitais ainda não atingiu os níveis de consumo pretendidos pela indústria ou pela visão otimista de muitos. Aliás, nem os níveis de consumo nem os de aceitação pelo leitor, ${ }^{13}$ a despeito da existência de belos projetos de edição digital. ${ }^{14}$ Muito embora haja motivos para se ter um dispositivo de leitura de e-books, também os há para se descobrir uma espécie de ecossistema das práticas de letramento, mesmo em países como o Brasil, considerado pouco letrado. ${ }^{15}$ Nossa desconfiança é a de que os mecanismos de legitimação da literatura estejam também em busca de legitimar os suportes de leitura, nomeadamente o e-book, empreendendo esforços na direção da publicação de obras digitais e do fomento à leitura em dispositivos eletrônicos. O objetivo de descobrir novos autores ou de fomentar a criação literária para movimentar um segmento da economia transborda então, a fim de atingir também a produção de obras que estimulem o consumo de e-books e, é claro, de
12. THOMPSON. Mercadores de cultura.

13. Algumas pesquisas esparsas dão conta de que o leitor tem mesclado seus dispositivos de leitura conforme sua vontade, não confirmando uma noção de concorrência e exclusão entre livros e outras mídias.

14. Ver uma breve análise em ALBARRAN; RIBEIRO. As fronteiras do livro.

15. É o que dizem pesquisas como a Retratos da Leitura ou o Functismo dos e-books, ver ENDO. (Re) imaginando o eBook e a cadeia de produção do livro digital; e para uma discussão sobre a recepção dos e-books por leitores, ver MELLO JÚNIOR. A recepção do e-book no Brasil: uma pesquisa quantitativa com leitores nativos e imigrantes digitais.
EM TESE
BELO HORIZONTE
v. 22
N. 3
SET.-DEZ. 2016
RIBEIRO. Literatura contemporânea brasileira, prêmios literários e livros [... ] P. 122-138 
16. O prêmio Nestlé foi criado em 1982 com o nome de Bienal Nestlé de Literatura e, em 1993, passou a se chamar Prêmio Nestlé de Literatura Brasileira. Foi extinto ha muitos anos, mas ajudou a revelar gerações de escritores, tais como Marçal Aquino e Antônio Cícero, entre outros. Ver na Wikipedia: <https://goo.gl/q51Gyb>. Acesso em: 31 dez. 2016.

17. O prêmio Sesc de Literatura foi ançado em 2003 com o objetivo de identificar escritores inéditos para edição e circulação nacional. Além do prêmio em dinheiro, as obras vencedoras são publicadas pela editora Record e distribuidas em todas as salas Sesc de leitura pelo Brasil. Ver em <https://goo.g/ CaL693>.

18. Prêmio recentíssimo, lançou em 2016 seu regulamento cujo objetivo era revelar romances inéditos. É ligado à Amazon com o apoio da editora Nova Fronteira. Oer em: <htps.//goo.gl//VreSA>. Acesso em 30 dez. 2016

19. Estados como Paraná, Rio de Janeiro e Pernambuco e prefeitura como Manaus ofereceram ou importantes. Por silerários prêmio Paraná teve edič̃ó 2012, 2013 e 2014 e riçós em 2017, boa premiação em dinheiro, publicacão das obras inéditas e resgate de livros importantes que estejam esgotados. >>> dispositivos eletrônicos dedicados à leitura. Mas como os prêmios literários têm se relacionado com isso?

\section{PRÊMIOS LITERÁRIOS NO BRASIL CONTEMPORÂNEO}

Muitos prêmios literários movimentam o Brasil, nas últimas décadas. Alguns são ligados a empresas ou à iniciativa privada, como o extinto Prêmio Nestlé, ${ }^{16}$ o atual Prêmio Oceanos, o Sesc ${ }^{17}$ ou o Kindle ${ }^{18}$ e outros, ligados a prefeituras e estados brasileiros, ${ }^{19}$ integrantes de ações relacionadas a políticas públicas muito recentes no país. Todos eles, no entanto, serão mais jovens do que o Jabuti ou o Cidade de Belo Horizonte, com suas respectivas características, a serem vistas mais adiante.

O antigo Prêmio Portugal Telecom, atual Oceanos, fo criado em 2003 pela empresa de telecomunicações portuguesa para valorizar a literatura brasileira, mas logo, em 2007 ampliou seu escopo para escritores lusófonos. Essa ampliação deu a ele uma característica transnacional que terminou por ampliar os nomes e a circulação de obras em vários países de língua portuguesa, resultando em uma evidente ampliação de mercados. Talvez se possa afirmar que o Portugal Telecom, que ocupa nossa mídia por vários dias quando acontece, é um dos responsáveis por conhecermos melhor alguns escritores portugueses ou africanos no Brasil hoje - não podemos afirmar que o mesmo ocorre daqui para outros continentes. Nos dias que correm, com a mudança de empresas, o Portugal Telecom tornou-se Oceanos e passou a ser organizado pelo banco Itaú, o que ainda mostrará seus efeitos. ${ }^{20}$

O Prêmio Governo de Minas Gerais de Literatura, uma das melhores premiações atuais, em termos financeiros, para obras inéditas foi criado em 2007 com o fito de estimular a criação em Poesia, Ficção (conto), Jovem Escritor e Conjunto da Obra, auxiliando na divulgação de "nomes nacionais e abrindo espaço para os jovens escritores mineiros", por meio de uma espécie de "bolsa" para autores de menos de 30 anos. São objetivos expressos do regulamento, no item 1, conforme as categorias agraciadas, com grifos nossos:

\section{DOS OBJETIVOS}

1.1. O Edital Prêmio Governo de Minas de Literatura tem como objetivos:

a) Promover e divulgar a literatura mineira e brasileira no País e no exterior por meio de premiação que homenageie autor vivo e brasileiro e que, pelo conjunto da obra, tenha contribuído de forma significativa para a divulgação da literatura brasileira no país e no exterior.

b) Promover e divulgar a literatura mineira e brasileira, em língua portuguesa.
19. > > > Para outros exemplos, ver os prêmios literários Cidade de Manaus em <https://goo. gl/WYrq2C > e o prêmio Cep Nacional de Literatura, em Pernambuco, em <https://goo.gl/ H3TNhu $>$. Diversas cidades do Brasil contam com prêmios de menor divulgação, mas também importantes, como é o caso de Campos dos Goytacazes, com o Concurso Nacional de Contos José Candido de Carvalho, que já passa das 26 edições. Ver em Janeiro por moio Estado da Cultura e da Fundãa Cesgranrio tem promovido prêmio homênimo da cidade há três edições, com duas categorias importantes: obra publicada novo autor fluminense.

20. Ver sobre o Oceanos em <https:// goo.gl/Pu7sBM>. O prêmio é, banco, o Itaú, também ligado a um dos maiores grupos editoriais nacionais, o Grupo Companhia das Letras, atualmente sob sociedade com a Random House, um dos maiores do mundo. Ver histórico resumido em: < https://goo.gl/ DMDqpF $>$. No mesmo blog é possível conhecer todos os selos da Companhia, que faz um trabalho agressivo e competente na aquisição e na divulgação de seus autores e livros.

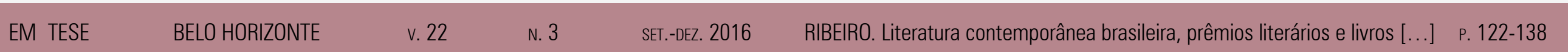


21. MINAS GERAIS. Edital Prêmio Governo de Minas Gerais de Literatura.

22. O Prêmio São Paulo de Literatura foi criado em 2008 para integrar da Cultura de São Paulo. Seu objetivo era "estimular a produção premiando anualmente autores e obras que se destacam pela obras que se destacam pela literatura de nosso país". Outro objetivo foi o "estímulo aos novos talentos" e o "fortalecimento das políticas públicas do livro e da leitura no Estado de São Paulo" (SÃO PAULO. O prêmio). Este é, sem dúvida, o prêmio de mais alto valor do Brasil: $\mathrm{R} \$ 400$ mil, ao todo. c) Incentivar tanto escritores já inseridos no mercado editorial como novos criadores.

d) Estimular a produção literária mineira. ${ }^{21}$

Já o prêmio Sesc, também muito visado, premia, desde 2003, obras inéditas sob pseudônimo, oferecendo, além de prêmio em dinheiro, contrato com grande editora (Record) e ajudando a revelar nomes que têm se fixado entre os novos autores da literatura brasileira.

O cobiçado e midiático Prêmio São Paulo de Literatura outro exemplo atual, foi criado em 2008, com o objetivo de premiar obras já publicadas, em suas categorias (atualmente, autor, autor estreante com mais de 40 anos e autor estreante com menos de 40 anos)..$^{22}$ Trata-se, portanto, de um prêmio de vocação muito diversa dos dois anteriormente citados, a despeito de fazer parte de ações de fomento e revelação da literatura brasileira. Para amenizar essa característica reiterativa mas certamente de valorização, o PSPL tem premiado, em seus poucos anos de existência, além de boas obras de editoras poderosas no cenário nacional, alguns autores e editores que se revelam, a despeito de serem pequenos e independentes, embora quase nunca estejam fora do eixo Rio-SP.

O estado do Rio de Janeiro, há cerca de três anos, tem promovido uma premiação com características híbridas. O Prêmio Rio de Literatura aceita inscrições em duas categorias: na de obras publicadas, a ideia é premiar livros e autores que já têm circulação; na categoria de novo autor fluminense, a intenção é revelar talentos nascidos no estado. Trata-se, portanto, de uma mescla de funções, com certa proteção da criação ali nascida e desenvolvida. São palavras retiradas do site oficial do PRL:

A primeira edição do Prêmio Rio de Literatura, projeto da Fundação Cesgranrio em parceria com a Secretaria de Estado de Cultura, recebeu mais de 600 inscrições. A categoria "Obras Publicadas" teve 356 obras inscritas; na categoria "Novo Autor Fluminense", foram 195 inscrições. No total, 35 editoras de todo o Brasil inscreveram autores, entre elas Companhia das Letras, Record, Rocco, Cosac Naify, Intrínseca, Planeta, Zahar e Leya. ${ }^{23}$

Destacamos disso que citar os nomes de grandes grupos editoriais ajuda a compor um discurso de legitimação não de autores e editores, mas do próprio prêmio, ainda jovem em nossa paisagem literária.

É interessante notar a proliferação dessas premiações, o que certamente movimenta um mercado literário no Brasil, ainda que isso nem sempre se exprima nos números e nas vendas desses títulos. Talvez se possa afirmar que a movimentação grande da imprensa e dos próprios escritores em torno dessas premiações não consiga ainda atingir as profundezas do
23. RIO DE JANEIRO Prêmio Rio de Literatura.
EM TESE
BELO HORIZONTE
v. 22
N. 3
SET.-DEZ. 2016
RIBEIRO. Literatura contemporânea brasileira, prêmios literários e livros [...] P. 122-138 
24. PREFEITURA DE BELO HORIZONTE. Edital Prêmio Cidade de Belo Horizonte. mercado editorial do Brasil, especificamente no "nicho" dos literários. No entanto, essas tentativas de movimentação não são todas dos anos 2000, como pode parecer com base no histórico recente dos prêmios citados antes.

A existência de prêmios literários brasileiros muito conhecidos remonta ao século XX. Certamente, ocorrências menos conhecidas existirão, dormentes entre lapsos de história pouco investigados, mas os prêmios mais amplamente conhecidos contam algumas décadas de existência. É o caso, por exemplo, do Prêmio Cidade de Belo Horizonte, criado em 1947 - 11 anos antes do Jabuti, em comemoração ao cinquentenário da capital mineira. É, portanto, o prêmio literário mais antigo do país, segundo histórico do site da Prefeitura de Belo Horizonte. ${ }^{24}$ A missão desse tipo de premiação é fomentar o surgimento de novos autores, em diversos gêneros literários, valorizando obras inéditas de autores que concorrem sob pseudônimo. Em 2016, o Cidade de Belo Horizonte contava com cerca de 1.700 inscrições de autores de todo o país e brasileiros que residem no exterior. Também na capita mineira, por meio de sua Fundação Municipal de Cultura ocorre o Concurso João-de-Barro, dedicado especificamente à literatura infantil e juvenil.

O Prêmio Jabuti teve início em 1958, por meio da Câmara Brasileira do Livro, sob as diretorias de Edgar Cavalheiro e, subsequentemente, Diaulas Riedel, tendo como vencedores de sua primeira edição Jorge Amado (com Gabriela, Cravo e Canela, romance), Jorge Medauar (com Água preta, contos) e elegendo Sérgio Milliet como personalidade literária do ano (1959). Entre as categorias premiadas estavam História literária, Ensaios literários, Ilustração, Literatura infantil e Literatura juvenil. É oferecido a obras já publicadas e relativamente conhecidas do público.

O Jabuti ${ }^{25}$ nasceu em um contexto social, política e editorialmente muito diferente do atual. Foi proposto com a intenção de estimular a articulação do segmento de edição, embora não contasse com o "entusiasmo" dos dirigentes da $\mathrm{CBL}$, na época. O interesse era premiar autores, editores, ilustradores, livreiros e gráficos de destaque. Ao longo de sua história de quase seis décadas, o Jabuti passou por repaginações e ajustes, assim como foi cobiçado e sofreu muitas críticas. Atualmente, é reconhecidamente o mais importante e talvez mais popularmente conhecido prêmio literário brasileiro dado a autores de livros já publicados, ao lado dos prêmios da Biblioteca Nacional e ao Prêmio Oceanos, não exclusivamente brasileiro. Se nos idos dos anos 1960, o Jabuti era entregue sem pompa em uma sala da sede da CBL, em São Paulo, atualmente conta com uma festa em espaços nobres do país: a Sala São Paulo ou o auditório do Parque do Ibirapuera.

Quanto ao seu regulamento, o prêmio, que contava com apenas sete categorias quando foi criado, conta atualmente
25. O curioso nome do prêmio devese às ideias daquela época de "valorização da cultura popular brasileira, nas raízes indígenas e africanas, nas suas figuras míticas, símbolos seculares carregados de sabedoria e experiência de vida e legados de uma geração à outra" História Prêmio Jabuti) Segundo o site da $C B L$ o nome foi inspirado em um $\mathrm{CBL}$, O nom Lobato. A estatueta é obra do

escultor Bernardo Cid de Souza

Pinto, após vencer um concurso.
EM TESE
BELO HORIZONTE
v. 22
N. 3
SET.-DEZ. 2016
RIBEIRO. Literatura contemporânea brasileira, prêmios literários e livros [...] P. 122-138 
26. CÂMARA BRASILEIRA DO LIVRO. História. Prêmio Jabuti. com 27 premiações, visando a estimular todas as etapas das redes do livro. Nos últimos anos, o número de inscrições para concorrer à estatueta chega a mais de 2.500 e a festa de entrega é um grande evento, inclusive midiático. Em 2015, a inovação no Jabuti ocorreu por conta da inclusão de uma nova categoria, que nos interessa de perto neste artigo: Infantil digital, abarcando "conteúdos para o público infantil combinados a elementos multimídia interativos". ${ }^{26}$

Apenas com esses exemplos é possível compreender que os prêmios literários, sejam eles oferecidos a obras inéditas ou a obras publicadas, são parte a se considerar nas redes de edição, incluindo-se questões de legitimação de autores, editores e outros personagens do circuito de criação artística ligado ao livro e à leitura. Muito embora sejam criticados como mecanismo de seleção ou legitimação, considerados excludentes ou distorcidos em relação à cultura do país, todos os prêmios existentes no Brasil expressam como objetivo a movimentação do segmento editorial e, mais especificamente, da literatura brasileira, o que significa não apenas sua valorização, mas sua continuidade diversificada e renovada, ao menos em tese.

A disputa acirrada por prêmios literários se confirma a cada ano. Autores inéditos tornam-se relativamente conhecidos após a edição de suas obras por editoras parceiras desses prêmios e outros, já conhecidos do público, angariam mais espaço na imprensa, em todas as plataformas, após polêmicas ou debates decorrentes de episódios ligados às premiações. Aspirantes a escritores veem-se impelidos a participar desse tipo de concorrência, assim como observam, não sem alarde em redes sociais, os resultados. Os circuitos da edição, cujas órbitas têm dimensões diversas, certamente não ignoram a existência de prêmios por todo o país, mas especialmente ligados aos estados do Sudeste, hipercentro do mercado editorial nacional e do debate literário, certamente com distorções e injustiças. ${ }^{27}$

\section{LIVRO E LIVRO DIGITAL}

Como já mencionado, o Prêmio Jabuti incluiu no edital de 2015 as obras da categoria "Infantil digital" ${ }^{28}$ Muito além de romances e poesia, a láurea alcança livros técnicos, profissionais da edição e adaptações de todo tipo. Tornou-se uma premiação que movimenta toda a rede do livro e da leitura, e não apenas autores e editores. O romance ganhador de 2015 foi Quarenta dias, de Maria Valéria Rezende, pela editora Objetiva. Na poesia, o autor carioca Alexandre Guarnieri venceu com o título Corpo de festim, publicado por uma pequena editora do Rio de Janeiro, a Confraria do Vento. O terceiro lugar acompanhou essa tendência, sendo a pequena editora Patuá, de São Paulo, a vencedora, com o título $A$ comédia de Alissia Bloom, de Manuel Herzog.
27. A escritora Maria Valéria Rezende, ganhadora do Jabuti de 2015, em entrevista ao jorno loG $O$ ḩa: "No Brasil sempre foi assim: 0 sujeito que queria ser escritor tinh que se mudar para Rio de Janeiro ou para São Paulo. É claro que isso cria distorções" (REZENDDE Maria Valéria Rezende lança romance inspirado em sua atuação contra ditadura). Maria Valéria é natural de ditadura). Maria Valeria e natural de em Joấo Pessoa, na Paraíba.

28. Para ver o regulamento de 2016: <https://goo gl//hG5V/s em: 27 dez. 2016. Em 2017, o regulamento está em: < https:// goo.gl/czb5wk>. Acesso em: 25 jun. 2017. No mais recente edital, jun. 2017. No mais recente edital,
$\mathrm{o}$ item sobre livros infantis digitais altera suas regras, exigindo ISBN das obras inscritas. É interessante observar essa mudança, que emprega a Lei do Livro (n. 10.753/2003) como fundamento 
29. O site estava no ar em: <http:// www.storymax.me/pt/>. Acesso em: 28 dez. 2016. Em 2017, não está mais, o que também é motivo de reflexão. Ver uma notícia sobre a empresa em: <http://minasinova. com.br/startup-faz-livrosaplicativos-de-classicos-adaptadosao-publico-juvenil/>. Acesso em 25 jun. 2017.
O livro infantil digital merecedor do Jabuti 2015 foi $\mathrm{Meu}$ aplicativo de folclore, de autoria do renomado escritor Ricardo Azevedo, pela editora Ática. O segundo lugar foi dado ao título Via Láctea de Olavo Bilac, de Samira Almeida e Fernando Tangi, pela editora Storymax, e o terceiro foi Flicts, obra muito conhecida de Ziraldo, pela editora Melhoramentos e Engenhoca. Diante desse elenco, é possível dizer que a in clusão da possibilidade de concorrer com livros digitais a um prêmio considerado importante para a literatura brasileira movimenta não apenas um mercado de adaptações editoriais como deve ter sido o caso de Flicts, mas também as parcerias entre editoras convencionais e novos modos de editar, em cooperação com programadores e outros esquemas profissionais. Provavelmente, iniciativas assim farão surgir editoras que operam sem pensar no impresso ou apenas tomando-o como referência para a criação de novos modos de editar circular e consolidar qualidade em livros digitais. Não é de se esquecer, no entanto, que as editoras contempladas, à exceção da Storymax ${ }^{29}$ são grandes e conhecidos grupos editoriais, com cacife para se estenderem às novas possibilidades.

A Storymax assim se define, em seu site, com grifos nossos:

StoryMax é uma publicadora de app books - livros digitais interativos para tablets e smartphones - que tem como missão tornar a leitura mais atraente e envolvente para crianças e jovens do mundo inteiro. Nossos app books são clássicos literários, bem editados e ilustrados, com animações, sons e interatividades que tor nam a leitura mais imersiva e engajadora. Pensamos conteúdos complementares para uso em sala de aula, visando aprofundar discussões e colher o melhor da experiência de leitura e, por isso nossos livros já são adotados por centenas de escolas nos Estados Unidos e também no Brasil. Fundada em 2012 com a publicação do app book Frankie for Kids, StoryMax chamou-se Y+B Digital Content por quase dois anos - período em que ganhou seus primeiros prêmios internacionais e integrou eventos pelo mundo. Ao participar do SEED - programa de aceleração e investimento semente para startups em Minas Gerais - tem estruturado seu modelo de negócio e iniciado parcerias importantes para levar leitura como lazer, aprendizado e reflexão aos jovens leitores do século XXI.

Destaque-se a descrição como "publicadora de app books", e não editora, nos moldes tradicionais. Também é de se notar a ênfase dada a um discurso sobre atração de leitores, envolvimento maior com eles por meio de tecnologias digitais, interatividade (um velho argumento de vendas, como já tratávamos anteriormente, ${ }^{30}$ apoiados em Sfez $\left.{ }^{31}\right)$. Trata-se de um discurso que põe a solução para questões de leitura e letramento nas mãos da tecnologia, especialmente a nova e digital, oferecendo obras clássicas em novas roupagens, sem enfrentar questões que vão além disso e que tocam a
30. RIBEIRO. Discursos sobre leitura e interatividade em reformas gráficoeditoriais de jornais impressos em tempos de tecnologias digitais.

31. SFEZ. Crítica da comunicação. 
renovação da literatura brasileira. A empresa, muito jovem e ainda pequena, é uma start up paulista, fomentada e impulsionada por um programa do governo do estado de Minas Gerais, com objetivos além fronteiras. O fato de ganhar prêmios importantes auxilia na legitimação desse novo modelo de negócios, conforme a própria Storymax afirma sobre si, em sua página de apresentação.

Os livros digitais infantis aparecem no Prêmio Jabuti no item 3.19 do regulamento e mereceram esclarecimentos, certamente na tentativa de cercar situações difíceis ou inesperadas quanto à premiação, em uma categoria ainda tão nova. Vejamos, com nossos grifos:

\subsection{INFANTIL DIGITAL}

O Prêmio Jabuti 2016 aceitará inscrições de livros digitais, compostos por textos literários destinados ao público infantil, que

3.19.1 Possuam conteúdo textual integrado a elementos multimídia, interativos e hipertextuais.

3.19.2 Disponham de capa (ou tela inicial) com o título do livro digital e acesso direto aos diferentes conteúdos.

3.19.3 Junto com a ficha de inscrição, o responsável por inscrever o livro digital nesta deverá fornecer o link para acesso ao mesmo, acompanhado de login e senha válidos.
3.19.3.1 A CBL não se responsabiliza pela desclassificação de um livro digital caso a senha enviada não permita acesso integral e livre a ele em máquinas de uso corrente no Brasil.

3.19.3.2 Os livros digitais não concorrem a livro do ano ficção. 3.19.3.3 Excepcionalmente, livros digitais inscritos nesta categoria estão isentos de apresentação da ficha catalográfica e ISBN. ${ }^{32}$

Note-se uma definição inicial de livro digital infantil, com a integração de modos semióticos e o acesso ou link direto. Interessante destacar a exposição de novas relações como a capa/tela, o acesso por meio de senhas e log ins, a compatibilidade com máquinas “de uso corrente no Brasil”, a possibilidade de não apresentar ficha catalográfica e ISBN, além da exclusão destes livros da categoria de "livro do ano". ${ }^{33}$

Dos editais publicados pelos prêmios citados neste trabalho, sejam eles para obras inéditas ou já publicadas, apenas o Jabuti ampliou-se em direção aos livros digitais. Esse tipo de ação não surpreende, já que parte da Câmara Brasileira do Livro, instituição fortemente relacionada ao mercado e às redes de edição, em todas as suas etapas. Outros editais e regulamentos de 2016, como o do Prêmio São Paulo de Literatura, ${ }^{34}$ o Cidade de Belo Horizonte, ${ }^{35}$ o Sesc e o Governo de Minas Gerais, para citar apenas alguns, sequer mencionam a palavra "digital" nos documentos. O caso de prêmios como o do governo de Minas ${ }^{36}$ ou o Cidade de
32. CÂMARA BRASILEIRA DO LIVRO. Prêmio Jabuti 2016. Regulamento, p. 5.
33. Como já mencionado em nota, no regulamento do Jabuti 2017, a CBL passa a exigir número de ISBN e categoria Infantil digita mantendo a decisão de estes livros ñ̃o .

34. Ver $<$ https://goo.gl/TvtdHv> Acesso em: 28 dez. 2016.

35. Ver $<$ https://goo.gl/twNiMF> Acesso em: 28 dez. 2016.

36. Ver <https://goo.gl/oUCRsC $>$. Acesso em: 28 dez. 2016. 
37. Ver $<$ https://goo.gl/g5tX9a $>$. Acesso em: 28 dez. 2016 .

38. RIO DE JANEIRO. Prêmio Rio de Literatura, Edital 2016. Grifos nossos.
Belo Horizonte é específico, já que se trata de premiação para obras inéditas, ainda não processadas por editoras. No entanto, um livro literário digital de qualidade talvez possa concorrer, no futuro, quando esse tipo de obra for considerado entre as possibilidades. Muitos escritores têm trabalhado em livros cujos formatos escapam quase completamente à noção de livro impresso, como é o caso do poeta Álvaro Garcia, em Poemas de brinquedo (narrado pelo poeta Ricardo Aleixo). ${ }^{37}$ Trata-se de uma iniciativa que provavelmente ganhará outro tipo de prêmio, se não estiver prevista nas redes da criação editorial.

O Prêmio Rio de Literatura faz menção a obras digitais no item 2 de seu regulamento, que diz respeito às condições de participação dos candidatos. No entanto, trata-se de aspecto ligado ao ineditismo da obra, item obrigatório para a participação. O cálculo dos $25 \%$ ficará a cargo do candidato.

2.2.4 - A obra inscrita deve ser inédita, nunca tendo sido publicada. Entende-se por publicação o processo de edição de uma obra literária impressa ou digital e sua distribuição física ou virtual, em livrarias ou pela Internet. Será permitida a inscrição de obra cuja pequena parcela do conteúdo tenha sido publicada anteriormente em blogs pessoais ou revistas eletrônicas, desde que não ultrapasse $25 \%$ do total da obra. ${ }^{38}$
Já o Prêmio Oceanos ${ }^{39}$ define, em seu regulamento, livro como um tipo de criação tanto impressa quanto digital, no entanto, exige-se ISBN para a participação.

\section{CONCORRENTES}

1.1. Oceanos - Prêmio de Literatura em Língua Portuguesa 2016 contemplará obras que atendam a todos os seguintes pré-requisitos:

1.1.1. Livros de criação literária - poesia, prosa de ficção, dramaturgia (com exceção de adaptações) e crônica - escritos originalmente em língua portuguesa, publicados em versão impressa ou digital.

1.1.2. Livros com primeira edição no Brasil entre $1^{\circ}$ de janeiro e 31 de dezembro de 2015.

1.1.3. Livros com primeira edição nos demais países lusófonos entre $1^{\circ}$ de janeiro de 2012 e 31 de dezembro de 2015 , desde que:

1.1.3.1. os livros tenham sido editados entre $1^{\circ}$ de janeiro e 31 de dezembro de 2015 por editora sediada no Brasil e publicados no Brasil nesse mesmo período.

1.1.4. Livros com comprovação de registro ISBN emitido por órgão brasileiro, considerados os requisitos anteriores.

1.2. Não serão aceitas inscrições de livros infantis e juvenis, biografias, livros de ensaios e nos demais gêneros não ficcionais.
39. Ver $<$ https://goo.gl/t6m9Dk> Acesso em: 28 dez. 2016. 
40. Ver regulamento e informações em <https://goo.gl/NWew5m>. Acesso em 30 dez. 2016

41. THOMPSON. Mercadores de cultura.
1.3. Estarão sujeitos a desclassificação, sob critério da Curadoria, em quaisquer etapas do prêmio, livros que tenham substancial conteúdo já publicado anteriormente em obra de autoria do próprio autor

O caso específico do Prêmio Kindle de Literatura ${ }^{40}$ merece ser destacado. Trata-se de um prêmio recentíssimo, oferecido pela Amazon, a imensa livraria virtual responsável por grandes mudanças no modelo de negócios do livro nas últimas décadas. ${ }^{41} \mathrm{O}$ nome dado à premiação refere-se ao próprio dispositivo de leitura da Amazon, o Kindle, evidenciando a relação entre as obras a serem reveladas e a leitura de livros digitais.

O regulamento do Prêmio Kindle prevê um fluxograma bastante diferente do que temos visto em outros regulamentos e editais. Em primeiro lugar porque a definição de "romance", único gênero permitido, está aberta à ficção científica, fantasia, suspense, policial e outros que se espraiam para muito além do livro literário mais estrito. Em segundo porque a premiação se inicia com a autopublicação pelo autor, na plataforma de publicação que a Amazon já disponibiliza. Vejamos a alínea $a$ do item II do regulamento, com nossos grifos:

A inscrição no Prêmio será realizada mediante autopublicação de obras inéditas na plataforma Kindle Direct Publishing da
Amazon (a "Plataforma KDP"). As obras publicadas serão disponibilizadas para venda a consumidores finais, de acordo com os termos e condições da Plataforma KDP. Ao submeter a obra (a "Obra Inscrita”) para publicação, o(a) autor(a) deverá cadastrar a obra no programa KDP Select, indexá-la com a palavra-chave de pesquisa \#premiokindle e ao escolher a categoria que seu livro será cadastrado, selecionar "Ficção", dentro de Ficção selecionar "Romance", e alguma subcategoria existente dentro de "Romance", como por exemplo: Fantasia, ficção científica, suspense, histórico, romântico entre outras.

O julgamento das obras concorrentes é feito por comissões de especialistas indicadas pela Amazon e pela Nova Fronteira tendo como critério o "mérito literário". São, então, selecionadas dez obras finalistas, que terão um "plano especial de marketing na Loja Kindle”. Esses autores já serão remunerados, conforme normas da plataforma, pelas vendas de seus livros.

Dos dez livros pré-selecionados, três são semifinalistas e apenas um vence o prêmio, em uma cerimônia por ocorrer em janeiro de 2017.42 A obra vencedora será publicada e distribuída no formato impresso (!) pela editora Nova Fronteira, ${ }^{43}$ mas também na forma de audiolivro pela Audible Inc., além do prêmio de R\$ 20 mil em dinheiro. O(a) ganhador $(a)^{44}$ cederá os direitos de seu livro à Nova Fronteira e à Audible, conforme contrato, entre outras condições, ao que parece abrindo mão de seus direitos autorais, na forma convencional.
42. Quando este artigo estava sendo escrito, em dezembro de 2016, o prêmio ainda estava em andamento. Já em meados de 2017, pode-se contar o final da história: o Prêmio Kindle foi atribuido a uma autora, a professora Gisele Mirabai, pela obra intitulada Machamba. 0 perfil de livro procurado pode ser entrevisto pelos que estão atentos ao mercado editorial. Para uma notícia sobre o assunto, ver <https://goo.gl/qmebXp >. Acesso em: 25 jun. 2017.

43. A Nova Fronteira é uma editora convencional, hoje parte do grupo Ediouro, fundado no Brasil na primeira metade do século XX.

44. É importante mencionar os dois gêneros entre ganhadores de prêmios pois a discussão sobre a representatividade feminina na literatura brasileira é tema candente, embora não tratemos dele aqui, mas tratamos, de alguma maneira, em RIBEIRO. Edição e legitimação literária: vestígios em cartas de escritoras mineiras do século $X X$. Outro aspecto que vem sendo discutido, embora ainda pouco, é a onda de conservadorismo que afeta criação literária. >>>
EM TESE
BELO HORIZONTE
v. 22
N. 3
SET.-DEZ. 2016
RIBEIRO. Literatura contemporânea brasileira, prêmios literários e livros [...] P. 122-138 
44. >>> Que isso já ocorra às obras que passam pelo filtro escolarizado dos editais de compras governamentais é at compreensivel, mas também a regulamentos de concursos literários, é de se estranhar. Alguns prêmios têm incluído em seus editais alíneas que dispõem sobre textos ou obras que respeitem os bons costumes ou não atentem contra a moral, o que é digno de nossa perplexidade, em se tratando de literatura. Ver, por exemplo, Machado de Assis 2015 , que fas m "bem-estar e valores morais" $<$ "htps: / em: $31 \mathrm{dez} .2016$.
Consta ainda nas disposições gerais do regulamento que as inscrições ao Prêmio Kindle são gratuitas, sendo livre a quantidade de obras que cada autor pode inscrever; que a forma de inscrição será por meio da plataforma da Amazon, sendo que os livros ali publicados devem ter caráter exclusivo enquanto o concurso durar, até a data de divulgação final do vencedor, e a obra ganhadora será exclusiva, mesmo que o autor não assine contrato com a Nova Fronteira; que os autores inscritos cedem seus direitos de locação e assinatura das obras pela Amazon, sendo já remunerados; que só participam obras escritas por um único autor, sendo vedadas coautorias e obras póstumas; que obras que não ganharem o prêmio podem se manter na plataforma, se os autores o desejarem, mas podem também ser retiradas; e que o ganhador do prêmio e os finalistas já autorizam de antemão o uso de seus nomes, imagens e voz para divulgação em qualquer tipo de mídia, sem ônus para a Amazon, pelo período de um ano.

Trata-se, portanto, de um tipo bastante inovador de prêmio literário, com a utilização, desde a primeira etapa, de uma plataforma digital e de um modelo de negócios ainda muito recente para as redes convencionais de edição. Aspectos como os direitos autorais e o controle sobre a difusão da obra são substituídos por práticas muito novas, se pensarmos na história do livro. O Prêmio Kindle traz ainda outras reflexões à tona, já que o aspecto literário e artístico esteve relacionado a obras visivelmente trend, que costumam causar polêmica antiga sobre o que seja literatura e outras questões de difícil resposta. Livros de fantasia ou policiais que se tornam best-sellers são excelentes negócios para as empresas, mas nem sempre são associados à literatura, ao cânone literário e mesmo a outros prêmios. Também é curioso que, nesta premiação, um dos ganhos seja justamente a publicação impressa, por uma editora de renome.

Esse tipo de parceria se parece com a parceria Sesc/Record, no entanto as características dos livros ganhadores são bastante diferentes. Mencione-se também que o Prêmio Sesc mantém o circuito de publicações convencional, sem o uso de plataformas digitais. Sua intenção é revelar obras e autores da literatura brasileira, o que tem sido levado a efeito. Às vezes, são revelados autores realmente jovens e iniciantes, com talento evidente; outras vezes, as obras "reveladas" são de autores que, na realidade, já contam com anos ou décadas de experiência, além de não serem tão jovens, mas que terminam por encontrar sua primeira chance de serem vistos e valorizados por um prêmio nacional, com publicação por uma editora grande, do eixo Rio-SP. Na verdade, como a visibilidade fora do eixo é quase impossível, assim como o alcance nacional de um livro ou autor, esses prêmios são caminhos para se chegar ao foco dos holofotes, que não se movem em direção a outros espaços. 
45. É muito interessante o depoimento da escritora carioca Marta Sesc de 2015 com a do Prêmio que seque no blog Estud Antes que seque, no blog Estudos pesquisa do prof. Leonardo Tonus, na Universidade de Paris-Sorbonne 4. Diz a autora: "O circuito que um escritor normalmente demora a frequentar, um ganhador do Prêmio Sesc de Literatura conquista da noite pro dia. O.k., nem tanto; não se trata de um dia acordar escritor, porque para ganhar o prêmio o tal iniciante sempre tem uma intensa - $\mathrm{e}$ discreta - trajetória de escrita. Mas um telefonema (Marta, você ganhou o Prêmio Sesc) e pronto, acaba a discrição. De repente me vi catapultada ao tal circuito, antes de ter chance de naturalizá-lo como parte da vida de um escritor" (BARCELLOS. A literatura precisa
De fato, mais um efeito da profusão de prêmios existentes no Brasil - e que fique clara a necessidade de que existam e que sejam cada vez mais aperfeiçoados em seus regulamentos, além de disseminados - é a cascata que eles terminam por configurar. $\mathrm{O}(\mathrm{a})$ ganhador(a) de um prêmio para obras inéditas muitas vezes consegue a edição de seu livro por uma das poucas editoras que mantêm a hegemonia de mercado e de visibilidade no país. Com isso, passam, automaticamente, a frequentar os grandes eventos, ${ }^{45}$ as páginas de cultura dos jornais de ampla circulação, programas de TV e outras premiações para obra editadas, isto é, receber o Prêmio Sesc pode significar - embor isso não seja assim tão determinista - receber outros prêmios, tais como o Jabuti, o prêmio da Associação Paulista de Críticos de Arte de São Paulo (APCA, uma espécie de redoma para poucos que podem ser enxergados) e outros que servem para reiterar obras que já circulam com a força que somente grandes grupos editoriais conseguem ter. Uma lástima que sejam tão poucos em um país tão grande e tão diverso.

\section{CONSIDERAÇÕES FINAIS}

Desde pelo menos meados do século XX, por questões explicitamente ligadas ao estímulo do mercado editorial e, em bem menor escala, à formação de mais intensas práticas de letramento da população, o Brasil conta com premiações literárias de diversas naturezas. No decorrer do século, essas premiações foram ganhando corpo e número, trazendo-nos hoje a um cenário difícil de acompanhar. São dezenas, talvez centenas de prêmios oferecidos por diversas instâncias, como empresas, governos ou outros. Cada um desses prêmios está apoiado sobre um regulamento ou edital, que define não apenas normas de funcionamento e prazos, mas também o que seja literatura e o que seja um livro.

$\mathrm{Na}$ atualidade, um livro não precisa mais ser um objeto impresso e envolto em capas, como preconiza a Unesco. A literatura também desliza entre as obras artísticas candidatas a um cânone escolar ou nacional e livros de aspecto muito mais mercadológico, e pouco aproximado de questões de linguagem e criatividade. Em ambos os casos, no entanto, são objetos de negócio. Os prêmios, portanto, são parte de alguma etapa das redes do livro, promovendo o movimento da revelação de autores, obras, editores e mesmo fazendo pontes entre escritores e editoras de grande porte. Toda essa movimentação, no entanto, não necessariamente alcança leitor em massa ou modifica as questões de leitura, letramento e mediação no país.

O livro literário digital entra nos prêmios também para que algo se movimente nessa indústria. O prêmio legitima o livro dessa natureza, que passa a ser visto e aceito como uma das possibilidades "de valor", provavelmente estimulando outras editoras e autores a produzirem obras em outras plataformas, além do impresso. Por outro lado, os livros 
46. Para um exemplo evidente disso, era so observar a págin Storymax, que propagandeou fortemente o fato de ter ganhado um Jabuti, em uma explícita. demonstração de transferência de valor. Em junho de 2017 o site não está mais no ar. vencedores dessas premiações em categorias tão emergentes usam a chancela desses prêmios na tentativa de angariar a confiança e a visibilidade pelo público ou por outros autores e editores ${ }^{46}$ Os efeitos disso ainda estão por se revelar, tanto no mercado editorial brasileiro quanto na relação com os leitores/consumidores.

Um artigo é pouco para se tentar mostrar um circuito tão complexo e móvel como este dos livros, da literatura e do comércio de livros, em um país como o Brasil. Todos os prêmios, editais e empresas aqui mencionados e eventual mente analisados podem estar, no momento da leitura deste texto, em outros pontos do mapa dos estudos de edição: novos editais já surgiram, regulamentos foram alterados, novas tecnologias foram admitidas e autores foram revelados. No entanto, é preciso que se registre e discuta a configuração atual da questão, que se movimenta ao sabor da criação artística, é claro, mas principalmente das estratégias de associações, câmaras, governos, empresas e editores. Além disso, processos complexos, como o da hegemonia de alguns poucos estados brasileiros, criam distorções que terminam por abafar ou soterrar iniciativas que existem em todo o país, mas que não encontrarão espaço e voz. Com todas as limitações conhecidas, esperamos ter ao menos fomentado o debate sobre livro, literatura e as redes da edição brasileira.

\section{REFERÊNCIAS}

ALBARRAN, Alí A.: RIBEIRO, Ana Elisa. As fronteiras do livro. In: CONGRESSO BRASILEIRO DE CIÊNCIAS DA COMUNICAÇÃO, 36., Manaus, 2013. Anais... p. 1-15, 2013.

BARCELLOS, Marta. A literatura precisa circular. Entre selfies e livros. Estudos lusófonos. 19 out. 2016. Disponível em: <https:// goo.gl/6Bzddb >. Acesso em: 31 dez. 2016

BOGADO, Fernando. Dos hombres y un libro interminable. Roger Chartier y Carlo Ginzburg. Pagina 12, Radar Libros, 24 dez. 2016

CÂMARA BRASILEIRA DO LIVRO - CBL. História. Prêmio Jabuti. [s.d.]. Disponível em: <https://goo.gl/CWfAWX>. Acesso em: 26 dez. 2016

CÂMARA BRASILEIRA DO LIVRO - CBL. Prêmio Jabuti 2016 Regulamento. [s.d.]a. Disponível em: <https://goo.gl/LUWqk7>. Acesso em: $28 \mathrm{dez} .2016$.

DOMINGUES, Rachel Bertol; VIEIRA, Itala Maduell. O circuito do livro: formas de acesso à literatura na contemporaneidade (Brasil anos 2000). Revista Brasileira de História da Mídia v. 4 , n. 2 p. 79-87, jul. 2015.

ENDO, Whaner. (Re)imaginando o eBook e a cadeia de produção do livro digital. In: CONGRESSO BRASILEIRO DE CIÊNCIAS DA COMUNICAÇÃO, 39., 2016, São Paulo. Anais... Disponível em: <https://goo.gl/HG5Rde>. Acesso em: 31 dez. 2016. 
INSTITUTO PAULO MONTENEGRO/AÇÃO LEITURA. Inaf 2011/2012: Instituto Paulo Montenegro e Ação Educativa mostram evolução do alfabetismo funcional na última década. Instituto Paulo Montenegro, 5 fev. 2012. Disponível em: <https://goo.gl/GWNsED>. Acesso em: $30 \mathrm{dez} .2016$.

INSTITUTO PRÓ-LIVRO. Retratos da leitura no Brasil. $4^{a}$ edição. 2016. Disponível em: <https://goo.gl/fdiJzR>. Acesso em: 30 dez. 2016

MELLO JUNIOR, José de. A recepção do e-book no Brasil: uma pesquisa quantitativa com leitores nativos e imigrantes digitais. In: CONGRESSO BRASILEIRO DE CIÊNCIAS DA COMUNICAÇÃO 39., 2016, São Paulo. Anais... Disponível em: < https://goo.gl/ tqhXyY>. Acesso em: 31 dez. 2016.

MINAS GERAIS. Secretaria de Estado da Cultura.

Superintendência de Bibliotecas Públicas e Suplemento Literário de Minas Gerais. Edital Prêmio Governo de Minas Gerais de Literatura, 2016. Disponível em: <https://goo.gl/oUCRsC> Acesso em: 28 dez. 2016.

MINAS GERAIS. Secretaria de Estado da Cultura. Superintendência de Bibliotecas Públicas e Suplemento Literário de Minas Gerais. Governo de Minas Gerais entrega Prêmio Governo de Minas Gerais de Literatura. [s.d.]. Disponível em: $<$ https://goo.gl/bZmVVb>. Acesso em: 26 dez. 2016.

MUNIZ JÚNIOR, José de Souza. El libro argentino y la globalización editorial. Buenos Aires: Cursos Virtuales Instituto de Desarrollo Económico y Social, 2017.
PARANA. Secretaria da Cultura. Biblioteca Pública do Paraná Prêmio Paraná divulga resultado no fim de novembro [s. d]. Disponível em: <https://goo.gl/LXF155>. Acesso em 27 dez. 2016.

PREFEITURA DE BELO HORIZONTE. Fundação Municipal de Cultura. Edital Prêmio Cidade de Belo Horizonte. Disponíve em: <https://goo.gl/JLgBDB >. Acesso em: 26 dez. 2016.

REZENDE, Maria Valéria. Maria Valéria Rezende lança romance inspirado em sua atuação contra ditadura. Entrevista a Guilherme Freitas. O Globo, Cultura, 6 jan. 2016. Disponível em: <https:// goo gl/1exPL2>. Acesso em: 9 fev. 2016

RIBEIRO, Ana Elisa. Discursos sobre leitura e interatividade em reformas gráfico-editoriais de jornais impressos em tempos de tecnologias digitais. Estudos em Jornalismo e Mídia, ano VII, n. 1, p. 110-122, jan./jun. 2010. Disponível em: <https://goo.gl/ NoSaaU>. Acesso em 28 dez. 2016

RIBEIRO, Ana Elisa. Ler na tela: o que é, hoje, um livro? In: MARTINS, Aracy Alves et al. (Org.). Livros \& telas. Belo Horizonte: Editora UFMG, 2011. v. 1, p. 93-106.

RIBEIRO, Ana Elisa. The book is on the tablet: visadas no discurso sobre o livro digital na imprensa. In: CONGRESSO BRASILEIRO DE CIÊNCIAS DA COMUNICAÇÃO, 34., 2011a,

Recife. Anais... Disponível em: <https://goo.gl/t2vNkh>. Acesso em 28 dez. 2016

RIBEIRO, Ana Elisa. O que é e o que não é um livro.

Materialidades e processos editoriais. Fórum Linguístico

Florianópolis, v. 9, n. 4, p. 333-341, out./dez. 2012. Disponível em:

<https://goo gl/Wq3fod> Acesso em 2 dez. 2016. 
RIBEIRO, Ana Elisa. Questões provisórias sobre literatura e tecnologia: um diálogo com Roger Chartier. Estudos de

Literatura Brasileira Contemporânea, n. 47, p. 97-118, jan./jun. 2016

RIBEIRO, Ana Elisa. Edição e legitimação literária: vestígios em cartas de escritoras mineiras do século XX. In: CONGRESSO BRASILEIRO DE CIÊNCIAS DA COMUNICAÇÃO, 39., 2016a, São Paulo. Anais... Disponível em: <https://goo.gl/2iezo2>. Acesso em: 31 dez. 2016.

RIO DE JANEIRO. Secretaria de Estado de Cultura/Fundação Cesgranrio. Prêmio Rio de Literatura, [s.d.]. Disponível em: <https://goo.gl/3yqOEw>. Acesso em: 27 dez. 2016.

RIO DE JANEIRO. Secretaria de Estado de Cultura/Fundação Cesgranrio. Prêmio Rio de Literatura, Edital 2016, [s.d.]a. Disponível em: <https://goo.gl/dq9bJZ>. Acesso em: $28 \mathrm{dez}$. 2016.

SÃO PAULO. Secretaria de Estado da Cultura. O prêmio. [s.d.] Disponível em: <https://goo.gl/Dw3wje>. Acesso em: 27 dez. 2016.

SFEZ, Lucien. Crítica da comunicação. 2. ed. Trad. Maria Stela Gonçalves e Adail Ubirajara Sobral. São Paulo: Loyola, 2000

STORYMAX. Site. [s.d.]. Disponível em: <http://www.storymax me/pt/>. Acesso em: 28 dez. 2016.

THOMPSON, John B. Mercadores de cultura. Trad. Alzira Allegro. São Paulo: Editora Unesp, 2013 